\title{
The Dissemination of Wushu Education and Culture Based on the Concept of Development
}

\author{
Wei Zhang', a \\ ${ }^{1}$ School of Tianjin University Renai College, Tianjin 301636, China. \\ 348007179@qq.com
}

Keywords: development philosophy, Wushu culture, communication.

\begin{abstract}
We should combine Wushu education with its culture heritage. Wushu teaching is an important part of education content. Through the dissemination and promotion of martial culture, it can promote college students' values. Nowadays Wushu as sports teaching in colleges and universities is facing with marginalization problem. We should stand in the perspective of carrying Chinese traditional culture and strengthen the importance of Wushu, reverse "marginalized". In addition, it is necessary to spread the culture value of Wushu and strengthen the function of educating people. Facing with the culture communication problem of Wushu, we should strengthen the carding and extraction of martial culture, standing in the view of development, eclectic. Finding the breakthrough point, and pass down the Chinese traditional Wushu culture lively. Eventually, promoting the development of martial culture and spread Wushu spirit generation by generation.
\end{abstract}

\section{Introduction}

In order to search for the essence of good traditional culture, Chinese Wushu have thousands of years of profound cultural heritage and are our precious cultural treasures. The school is at an important position to educate teenagers [1]. During the two sessions in 2015, Chinese Wushu will be listed as one of the key to support programs of the ministry of education. In view of the importance of "Wushu" in traditional culture, the managers and decision-makers of college sports should take this point seriously and carry out the teaching of martial actively.

\section{The teaching of Wushu plays an important role of college physical education}

Wushu contains full of traditional culture, it is based on Chinese long history and civilization. Regarding fighting and routines of specific engagement action as the carrier, which reflects the traditional philosophy thought of the Chinese nation, national emotion, aesthetic taste and cultural characteristics, which has an independent complete system of cultural forms. In universities, it is of great significance to carry out the teaching of Wushu to promote national culture and build cultural confidence [2].

\subsection{Wushu is the "body language" of traditional culture}

Wushu culture gather the traditional philosophy of the Chinese nation in one place, which enriches the national emotion and aesthetic taste [3]. Wushu culture is closely connected with Chinese traditional culture, we can even say that Wushu culture is the epitome of Chinese traditional culture. Wushu culture can also be understood as the expression of "body language" of Chinese traditional culture. Chinese Wushu culture is an integral part of Chinese culture. Chinese traditional culture focuses on teaching, while Chinese Wushu focus on practicing, which plays an important role in cultivating the practical spirit and national emotion of contemporary college students.

\subsection{The function of Wushu}

Only Wushu has the characteristics of national traditional culture and the personality of the national culture. It is in conformity with the needs of national cultural construction. Chinese Wushu culture was influenced by multiple culture, such as Chinese ancient philosophy, ethics, medical, and aesthetics in the long-term process of formation and development. Its broad connotation and 
multiple function plays an important role in the cultivation of contemporary college students' values.

Chinese Wushu stick to the concept of "Military Morality Education" and "Military are based on morality". Traditional Wushu education can help students to build self-discipline and spirit of self-discipline. It plays an important role in cultivating people's social sense of responsibility, improve self-cultivation and maintaining social order. Especially in today's historical node of carrying forward the traditional culture of China. "Military are based on morality" as the core of reflecting the values of the people with "benevolence".

\section{The problem of Wushu teaching nowadays}

Due to complex reasons, the admiration of compatriots for western culture lead to the decline of traditional Chinese cultural status. In collegiate physical education, the development of sports programs are dominated by western sports culture. However, Wushu become a "sports project", and its unique cultural connotation is rarely reflected in the physical education. This phenomenon deserves our deep thought.

\subsection{The status of Wushu in physical education}

In the history of Chinese Wushu development, it holds an important status, and the "warrior spirit" has been deeply integrated into the blood of the Chinese people. However, due to a series of humiliating events in recent history, Chinese have produced a deep "cultural inconfidence". The former "national art" take a back seat to "sports" with modern western culture. In the sports teaching of colleges and universities, Wushu have been marginalized to the wrong idea of "a sports project". "Wushu of schools become the activity of physical education" means that we simply regard Wushu as a sports program, and the national spirit and cultural connotations has been ignored. The status of Wushu is increasingly marginalized in sports programs that are dominated by western culture. There is a tendency that less and less students want to learn Wushu as a sport course in colleges and universities. Therefore, in the understanding of Wushu, we should rise to the height of culture, reverse "Wushu is a sports program" erroneous concept, vigorously promote the spread of Wushu' culture in colleges and universities.

\section{2 The teaching of Wushu ignores the spread of Wushu' culture}

Wushu is a kind of culture, and this culture makes "Wushu" becomes to the soul of Chinese civilization. Wushu has only been taught as a sports program in colleges, but it does not pay attention on the spreading of Wushu' culture during teaching process. This can not only achieve the purpose of spreading Chinese Wushu' inheritance, but also can lead to the development of Wushu deformity, and at the end, we lose Wushu's spirits. Therefore, in the course of Wushu's teaching, the teachers should strengthen the guidance of Wushu' cultural consciousness and take it as the core of the whole Wushu' education. This is the real inheritance and promotion of Chinese Wushu. In the process of teaching in colleges and universities, teachers should change their focus on simply technical teaching, ignoring the teaching contents and methods of the Wushu' culture, roundly promoting Wushu' education function, realizing the comprehensive development of college students.

\subsection{Neglecting the function of educating people in Wushu teaching}

The unique function and value of Wushu' teaching is not to be replaced by other subjects. Through the study of Wushu, college students can learn about the traditional skills, traditional philosophy, traditional ethics, classical art and other cultural contents of the Chinese nation. Moreover, in the learning process of Wushu, it can cultivate students' important personality traits such as thinking, courage, confidence, tolerance and cooperation. The education not only makes learners' body strong and has help to grow self-defense functions, but also plays an important role in inheriting Chinese culture and carrying forward national spirit. Therefore, in the course of Wushu' teaching, we must insist on educating first. 


\section{Problems in the propagation of Wushu culture}

Many excellent ideas in Wushu culture have a profound influence on the peaceful development of the world today. However, due to the lack of understanding of a country, Wushu culture has encountered a bottleneck in the process of communication. Now, this problem has become increasingly prominent. Many domestic experts and scholars are aware of this problem. How to make a good inheritance and promotion of Wushu Culture? Some scholars said: We can absorb the experience in the promotion process of Wushu culture, and make contemporary transformation of the excellent traditional cultural value of Wushu. While we never forget the national character of Chinese culture, referring to the outstanding achievements of national culture, carding and extraction necessary for Chinese Wushu culture. We should open minded and inclusive world each country the national ideology and culture the essence, looking for accurate positioning promotion group. Therefore, the method of Taekwondo, which is quite similar to Chinese Wushu, has given us deep inspiration in the process of international popularization.

\section{1 Carding and extraction}

"To make a contemporary interpretation of the connotation of Chinese excellent traditional culture, and to harmonize the Chinese excellent traditional culture with the contemporary Chinese cultural value [4]. At the same time, to integrate into the world culture consciously and in the dissemination of good Chinese traditional culture to speak of love, pay attention to the people, advocate harmonious spirit, the pursuit of Great Harmony and harmonic relationship, has its contemporary value and the world significance to guide people to perform good deeds and thought resources. The development of Taekwondo project is of great significance for the promotion of Wushu. "Strengthen the traditional Taekwondo etiquette education in the development process, pay attention to moral education of the younger generation of German art practitioners, training objectives. In the traditional culture of refining, taekwondo combined with the psychological characteristics of the young students. It puts forward the "etiquette, modesty and self-control, patience and indomitable spirit of" five spirit, so that the essence of Taekwondo has more concise spirit[5]. It is easy to make in the promotion process by the clear spirit. In China traditional Wushu, first of all, because the culture broad and profound. In the promotion process, there is no clear guidance of the spirit of the audience, so that the audience can not clear the spirit meaning. It leads to them spiritual blindness and lax. It also brings adverse effect to the promotion of Wushu culture and Wushu. Therefore, we should refine the core values of the Chinese Wushu culture. Because "the core of culture is values, which determines the core of cultural identity, that is, the identity of values"[6].

Consequently, we should learn from the development model of Taekwondo. We should sort out the traditional Wushu. And we need take its essence and form a clear spiritual meaning, promoting the transformation of Wushu and cultural values by popularize according to the target audience, so as to promote the popularization of Wushu culture.

\section{2 Incorporate things of diverse nature}

Scanning the culture of Wushu from the strategic height and Promoting the development of Wushu culture through reformation. On one hand, we vigorously promote the culture of Wushu from the front. On the other hand, Chinese cultural identity should be put in the first place in the development of Chinese Wushu Culture, and extract the cultural symbols with the function of cohesive Chinese cultural identity. We should learn our Wushu culture from the perspective of the world, integrate the idea of "universality" into the Wushu culture, and avoid the opposition between eastern and Western cultures in the process of popularization and dissemination, so that we can be well accepted by the world. To strengthen the cultural identity of Chinese Wushu, only in this way can it promote the wide spread of Wushu Culture in the world, so as to improve the influence of Wushu culture. More importantly, we need to sort out and extract Wushu culture at the height of social development, eliminate the dross in Wushu culture and some content that no longer adapt to social development. What's more, endow the Wushu culture with the new connotation of the times 
and make it adapt to the development of the society. In order to have the characteristics of the times, Wushu must be given a new content of the times.

\section{3 Identify right group orientation to promote}

In order to develop sports, there must be a relatively fixed audience. This is the basic guarantee for the development of a project. When the target location of the audience is determined, it is necessary to carry out the project transformation according to the characteristics of the target[7]. On the road of popularization of Chinese Wushu and Wushu culture, it has the same effect to play the specific goal of the development of Wushu on young people. The successful promotion of Taekwondo in the world has also played a certain role in the development of Wushu. At the beginning of the popularization of Taekwondo, the target is clearly positioned on the audience of young students, and tightly grasp the generation of young people, from ideology or ideology to physical fitness.

\section{Conclusion}

Teaching Wushu in college is an important part of college physical education. We should connect the culture importance of Wushu during our courses. Wushu culture teaching content as an important part of the teaching content, promoting the formation of College Students' values through the popularization and promotion of Wushu culture. Besides, for the problem of marginalization of Wushu in today's college physical education, we should enhance our understanding of the importance of Wushu and reverse the "Marginalization" situation in the perspective of carrying forward the traditional Chinese culture. And we should strengthen the dissemination of Wushu culture and enhance the educational function of Wushu in sports teaching. Facing with the problem of Wushu culture transmission, we should strengthen combing and extracting Wushu culture. Stand at the angle of development, absorb everything and identify breakthroughs. Carry forward the Chinese Traditional Wushu culture lively, and promote the development and dissemination of Wushu culture.

\section{Reference}

[1] Zhou Aimin. Promote the Chinese Wushu into the campus and improve the soft strength of the culture from the doll to the.2015-07-01. (china.com.cn)

[2] $\mathrm{Hu}$ Yi. Looking at the value of Wushu from the perspective of Chinese traditional culture. Fighting and Wushu science. April, 2008, fifth volume and fourth.

[3] Wang Chun, Wang Boli: Research on cultural identity of Wushu in national cultural construction. Journal of Chengdu Sport University, 2015 (Vol. forty-first), fourth.

[4] The value identification and innovation of Chinese excellent traditional culture: Yu Hongbo “Guangming Daily”. Eleventh Edition in July 7, 2017.

[5] Meng Limei. South Korea Taekwondo Limei the origin and development of Journal of Mudanjiang Normal College, 2005 (1): 35.

[6] Jiang Hong, Wang Chaopin. Multi ethnic identity and national identity integration path of J. The ideological front, 2014 (2): 57.

[7] Cui Huaimeng: an analysis of the Enlightenment of Taekwondo to the success of the Olympic Games on the development of Wushu. 